\title{
UNIVERSITY INSTRUCTORS' REFLECTIONS ON THEIR FIRST ONLINE TEACHING EXPERIENCES
}

\author{
Dianne Conrad \\ University of New Brunswick \\ Fredericton, New Brunswick, CANADA \\ Email: dconrad@unb.ca
}

\begin{abstract}
Moving from traditional face-to-face teaching to teaching online can be a precarious process for instructors. In this qualitative study, I interviewed instructors who were engaged in online teaching, for the first time, in a graduate program at a Canadian university. All instructors had some postsecondary face-to-face teaching experience. In-depth interviews with the instructors showed that they had very little knowledge of the new medium they were entering and relied heavily on their face-to-face experiences and their own pedagogy. Instructors' reflections on their performances centered largely on their roles as deliverers of content. They revealed very little awareness of issues of collaborative learning, of learners' social presence, or of the role of community in online learning environments.
\end{abstract}

\section{KEYWORDS}

Novice online instructors, online teaching, instructional pedagogy

\section{INTRODUCTION}

How do instructors learn to teach online? What are their perceptions as they enter this new learning environment for the first time? That the nature of faculty preparation and support for online teaching vary, and that subsequent performances between inexperienced and experienced instructors also vary considerably $[1,2]$ prompted me to explore with several first-time online teachers the nature of their experiences. To that end, I focused this research on participants' understanding of themselves as novice online instructors [1].

\section{THE STUDY AND ITS CONTEXT}

In this paper, I use the term online learning to refer to computer-mediated, web-based learning environments. Asking the participants in the study to reflect on their roles as online teachers, I interviewed them twice, once before they began their new teaching experiences and again after they had finished.

The five instructors that I interviewed for this study were teaching courses at a Canadian university in an online graduate program that offered seven core courses and three elective courses. One instructor was a tenured professor in the faculty that offered the graduate program. Four of the instructors were sessionals, hired on the basis of their content expertise to teach specific courses, although all were connected to the university as member of other faculties. Two were also completing doctoral studies while teaching in 
other faculties. All instructors, in addition to teaching their courses, had served as content experts during course development.

I met with the instructors twice, for lengthy interviews of 60-90 minutes. The first interview was conducted prior to, or near the beginning, of the online teaching experience; the second interview was conducted at the conclusion of the teaching experience. One instructor's concluding interview was conducted by email. Six months after the interviewing period, I contacted the instructors again by email to ask for further reflections on their experiences.

As the lead member of the course development team and administrator of the graduate program, I had conferred with the instructors during course development, implementation, and delivery. I was also available to them as a resource while they taught, and I had access, with their knowledge and permission, to their online courses-access that I used at the outset of courses solely in an observational capacity. At several times, I was invited by instructors to observe and comment on incidents that occurred in their courses. These occasions were near the beginning of courses, when the novice instructors were still "finding their way" with the new medium.

Four of the instructors taught elective courses. One taught a core course. Because the program was cohort-based, core courses were restricted to program enrollees while elective courses were populated by a mixture of program participants and students from other faculties or universities. Each course had 13 to 20 participants and was offered via the Internet using WebCT software. Online readings and resources were supplemented by textbooks, packages of course readings, or both.

\section{RESULTS OF THE STUDY}

Following an interpretive, iterative approach to qualitative analysis [19], I worked with the study's data, slowly determining categories of responses and, from those categories, drew forth what I felt were the important themes. The following discussion presents the study's findings, using as a framework Collins and Berge's [12] work in which they categorized online instructional roles into four general areas: pedagogical, social, managerial, and technical. I begin with a discussion of the technical role, which seemed to be the role that was most easily separated from the others.

\section{A. Technology Issues: Mastering a New Medium}

Overall, learning or using the technology (WebCT) did not present significant challenges to or problems for the instructors. Robert, who had experience as an instructional designer and was familiar with online methodology, had also once studied by correspondence and used this prior experience with distance education as a benchmark. Having worked in such a system where "you get the material, you do your responses, you send them back, and then two or three weeks later ... you get the instructor feedback at about the time you've done the next thing ... [and so] you're about two steps back," he contemplated Internet technology in terms of its interactivity and temporality. As were Carl's and Mark's, Robert's reflections on the technology revolved mostly around the convenience it afforded them as instructors, in that they were able to choose when they would interact with the group. Robert contrasted that choice to the inflexibility of classroom appearances:

You're teaching in the classroom, and you have to be there at a particular time of day, and if that's not a particularly good time of day for you, and if you're not a morning person and your class starts at 8 am ... or if you've got a five-hour block, which will often happen in the summer course, they run the bulk of the day, you might find that that kind of environment 
isn't necessarily congenial to your own best methods for working.

Robert was forthright in admitting the personal interest that had motivated him to engage in online teaching, declaring: "Here again, I was hoping to see what would be the result for me, the instructor, as opposed to the students." Mark, in a similar but even more extreme vein, mused about the tax implications of being able to reside in another, more tax-favorable country and still earn Canadian dollars for teaching online. Mark was the least technically-experienced of the instructors I interviewed; he was one of the older instructors, and his usual teaching environment allowed him to lecture in traditional didactic ways with perhaps the addition of some overhead or Powerpoint slides. Like the other instructors, he found that teaching online was more time-consuming than his previous face-to-face experiences. "I would say, compared to the courses I'm regularly teaching, it's about 30 percent more time consuming, but then this is the first go, and it's learning the technology and methodology." Having said that, Mark acknowledged that "while WebCT was certainly all new," my pre-course demonstration to him of its "salient features" had allowed him to see that that it "wasn't opaque, as some things are. I felt it was doable."

In further discussion after the course had ended, Mark admitted that although he had been "quite apprehensive because computers make me nervous ... it turned out not to be as bad, partly because WebCT worked pretty well." Recalling Mark's earlier comments on "technology and methodology" relative to his investment of time, therefore, raised questions in me as to which aspect of the instructional role had actually consumed his time. In his comments, Mark did not clearly differentiate between his handling of the technology and any of the "methodological" issues-by which I assumed he meant pedagogical issues - associated with the online instructional venue.

\section{B. Pedagogical Issues: Learning Online}

Reflecting on their thoughts about teaching, in both pre-course and post-course interviews, the instructors that I spoke with raised a wide range of pedagogical issues, but each leaned heavily on the nature of their past experiences. To varying degrees and in different ways, they intertwined their reflections on pedagogical issues, those that revolved around "educational facilitation" [25] with management issues.

\section{Delivery of Content}

Robert was very pleased and happy that the Internet technology allowed him to so clearly present cogent chunks of information to his students. He described the process by which he wrote and re-wrote his messages and commented:

In this way of teaching, you not only have the opportunity to stop and reflect on what you're about to say, or write something and then read it later before sending it out, but you also have the opportunity to go out and do a little bit of research about that particular question.

He felt that his strengths as a teacher were optimized in this way-his passion for his subject, his tendency to "speak in quite an academic style"-and praised the ability of the free-flowing exchange of ideas made possible by online fora to create a strong learning ethic.

Robert observed that, at the beginning of the course, both he and his learners were "posting essays" in response to online discussion questions. I had pointed out to him, in our pre-course briefing, that learners were often inhibited by long, content-exhaustive postings and that there were strategies to encourage 
shorter, more conversational discussions: don't include salutations and closings in messages; keep messages shorter; ask questions to provoke thinking. Robert tinkered with his approach and found indeed that his online interactions became less rigid and more flowing. "The messages started almost immediately to become briefer. So the way they were responding in terms of the structure of the materials changed at that point."

He was bothered, however, by the way he perceived that the online "structure" didn't give him enough time on certain topics:

In terms of what the students [were] learning, there was one particular module that I considered the core of this course. None of the other people involved considered it to be that important, and, in fact, we started with that and expanded into other [topics], but I felt that people needed to learn this one set of material, and I wasn't satisfied what we did with it. The discussion question didn't deal directly with what had been in that module and there wasn't a lot of periphery discussion saying 'What about this idea? What about that idea?' So something needs to be done because it really is a central piece of what this is all about.

Robert felt that in a face-to-face teaching environment, discussion of that central topic could have been better integrated into the rest of the course, rather than off-loaded in one session. He also pointed out, in what was perhaps a related concern: he had found it difficult to look back through the many messages to retrieve ideas that had already been posted. He suggested that a keyword search tool would be a useful addition for online teaching so that instructors and students could more easily locate exchanges of ideas by topic.

Robert was very conscious of the import of his physical presence in face-to-face settings and reflected on his style of dress and physical actions as parts of his instructional actions. "People would look at me and I'd wave my arms or whatever." Online, however, "I had to find substitutes for those." Similarly, Bryan framed his understanding of how he would teach, his postures and his stances, in terms of his past experiences, although, knowing he would be teaching online:

I assumed that my role would change from a lecturer primarily to one as a facilitator. When I first started teaching, I did a lot of monologues. ... the primary role I had was that of a subject matter expert and, in the traditional sense, it was a talking head, at least most of the time.

After sitting through a number of coaching sessions with me in which we discussed online teaching styles, Bryan felt that he needed to "amplify the role of facilitator." To him, that suggested that he would:

Provide a structure and an environment in which the course topics would be covered ... and the students themselves would bring on content within the structure I provide. I need to provide content, but the content needs not necessarily be entirely mine. So that was a piece of architectural consideration-which I felt was idiosyncratic to an online course.

In addition to providing the structure within which content discussions would evolve, Bryan felt that he would be called upon to provide some leadership that would be tempered by, and predicated upon, students' own sense of self-direction and motivation:

I gave them, I thought, an opening, a challenge, an opportunity to be self-directed learners but, if they were directed the wrong way, or I felt uncomfortable with the direction they were taking the class, then I would have to intervene. And so I was, in my preparations, prepared to intervene and, in essence, be more heavy-handed. 
Victor had not previously taught online, but his pedagogical expectations came from work he had done in other areas of distance education. He felt that he "was quite aware of some of the pitfalls" that might occur and he was especially aware "of the need for a continued instructor presence, so I tried to log in often and make myself as visible as I could." He was happy that "for most of the course, the discussion forum seemed to work quite well. The students did a good job of keeping the discussion on track and seldom needed any intervention from me." In hindsight, however, Victor thought that perhaps he had entered discussions too early, imparting his knowledge and his biases and thereby influencing the nature and development of students' conversations. "I probably could have posted a little less and let the students get to the points themselves. I would have liked it too if some of the points had had longer discussion." Like Robert, Victor had a notion of how "long" certain discussions should be. Like Robert, he felt that certain discussions had ended prematurely and he didn't know how he could have motivated the students to continue along certain "threads" of topic discussion.

\section{Instructors' Dependence on Visual Cues}

Most of the instructors that I interviewed expressed concern about teaching in a medium that did not offer them visual access to their learners. Victor did not have a lot of teaching experience although he had conducted a graduate seminar on the same content as the online course he was teaching at the time of this research. Very self-effacing in his reflections of his teaching performance, he referred-only somewhat jokingly - to "looking for cringes and things like that" in his audience. He felt that teaching online left him "a bit in the dark." Bryan also reflected that teaching online left him unable to observe his learners for cues. "Online, everybody is a mystery until they disclose something."

Raising the issue of control in terms of his ability as an instructor to confront his students physically in traditional face-to-face learning environments, Bryan lamented the fact that online learners:

Have much better control of how much they disclose to me ... whereas, in face-to-face format, I can overcome some of those barriers. I can actually corner them, eyeball to eyeball. I can get a lot of information from them. I can't do it [online]. It's a very different medium. I don't even know what they look like.

Ultimately, however, he conceded that not having been able to see the learners "wasn't quite as big a handicap" as he thought it would be.

Both Robert and Carl also brought to the fore their concerns about not being seen by, and not seeing, their students. Robert, who customarily wore an expensive suit to the first day of face-to-face classes and then progressively "dressed down," in the style of becoming "authentic" [6] in the eyes of his learners, realized that the lack of visual cues worked both ways:

The students influence you by the way they look. If someone looks very professional, you tend to treat them a little more professionally. If they look like a slob, well, you think they're a more relaxed kind of person. So, there was a sense in which that was also good that they weren't visible to me, and yet, it did feel a little odd to be talking to complete strangers.

Carl considered the absence of physical presence differently as he reflected on how students' inability to see him would alter his teaching dynamic. Young and youthful looking, he was used to surprising graduate students by entering the lecture hall, making his way to the front of the class, and then revealing himself as the instructor.

The teaching situation is always somewhat contrived in that you walk into a classroom. Nobody knows until I go to the front and turn on the slides that I'm not one of the students, and it's my 
position right from the beginning. It's dictated by the fact that I'm the one at the front with the slides. And it's the same online: I'm the instructor; they are the students. And so that sets up a certain amount of credibility. ... It's different if I am wearing a tie or if I'm wearing a t-shirt. There's some natural structure there in terms of everybody's role, but I'm not too worried about the flow.

Mark's teaching experience had depended heavily on traditional lecture formats, supplemented with overheads, drawing on and guided by assigned textbook readings. After concluding his online course, he admitted that he was still more comfortable going into a face-to-face classroom, partly because, when online, "you don't see the students and you make a point online in written form and you can't see their body language or how they are reacting." However, Carl's view on gauging students' responses by watching their body language was considerably different:

You can't see them and their faces. I think that's a good thing. The interested people you'll hear from. What I found from the feedback [in face-to-face courses] is that some of the people who looked like they were dying thought it was the best course they ever took. So you can't really tell from their faces.

\section{Management Issues: Managing the Process of Learning Online}

Perhaps because the managerial function, involving "agenda setting, pacing, objective setting, rule making, and decision making [25] is so closely related to pedagogical and social roles, instructors did not clearly separate their reflections on their online teaching from reflections on their management processes. Of the management functions articulated by Collins and Berge [12], respondents were most forthcoming on issues of pacing. (Perhaps the absence of discussion on other management issues can be explained by the fact that the program in which they were teaching used a course template course model that clearly outlined objectives, agenda, and expectations at the outset of each course. This model reduced the need for a lot of discussion or negotiation on some management issues.)

In discussing pacing, and course management decisions, instructors used their past experiences as reference points, regardless of what types of experiences they had had. Robert's summer session teaching experience had necessitated the delivery of content in a compressed timeframe where the rate of learners' reactions was intensified given daily contact with them. He worried about the construction of the course and its seeming inability to be modified once mounted on WebCT.

There's also the fact that all of the material up there is essentially pre-packaged. Last night I was looking at next weeks' lecture and the week following, primarily next week's lecture, and thinking 'there are things I should have done differently based on what I now know about what the students do.' So do I go in now and modify the course materials?

Victor's teaching experience was largely based on workshops with adult professionals and he was very attuned to management issues that considered his learners' adult needs. He believed that online instructors should respond to requests quickly, show flexibility, "give opportunities to provide formative feedback to students so they know how you are likely to assess their class," and let learners know if the instructor will be absent from the conferencing forum for any significant period of time.

In his responses, Carl admitted to having thought more about his teaching during the interview process than he had prior to beginning the course. Carl had experience teaching both undergraduate and graduate classes in a business faculty. He was accustomed to delivering a mixture of lectures and case-based 
seminars. He felt that lecturing was based on "a legacy system" and likened the discussion fora of online courses to case-based seminar discussions, which he thought were more suitable to his personal style.

I much prefer the case study part to the lecture. I think it's easier for me, more natural for me to disseminate information without just lecturing. Doing it in real time and doing it as people come up with their comments and sort of go with the flow rather than giving information they might already know, or missing things that they don't know, that may be important, so in a discussion, I think that's a lot easier.

Carl judged that online discussion fora would create "a case-based course again" and thought that the advantage would be that "we can do [the learning] when we're interested in it." He described online interactivity as "flow" and reflected that, although he, as the instructor, had "the hammer,"

I think the flow develops naturally and ... even if it slows down, I'll try and speed it up and if it gets off-track, I'll try and direct it back to where it should be. Other than that, I'll pretty much leave it up to the group to discuss what they want to discuss.

Carl's comfort with freely flowing discussion, however, was tempered by his belief in the benefit of each learner's direct link to him, as instructor: "The discussion is only part of the class. Everyone also has the opportunity to learn individually through the case studies and feedback they get there. "As with the other instructors in this study, Carl's comments on timing and pacing bridged issues of pedagogy and management.

\section{The Silence Around Social Issues}

The instructors with whom I spoke contributed the least data on topic areas that fall into Collins and Berge's social domain, the "promotion of the friendly social environment essential to online learning" [25]. Robert had attended an international conference on online learning and had heard there that one of the "most difficult things to accomplish in a course, and the most crucial thing, is this sense of community involvement among the students." He did not refer to a "sense of community" again, however, except to mention that he thought that, as a group, his class had "learned a lot about the way other people think. How they tend to do things." This had occurred through the exchange "of personal notes and private mail notes."

Carl, when asked directly about the creation of a sense of online community, commented on its importance in another content field that he was familiar with and then added, "But the only thing better than community is personalization. Community is important but the chance to really connect with students is one on one." Although he thought that one-on-one relationships with students would serve to complement a sense of community, he felt that "even if the community feel of the course is not very good, [learners] can still have a good course through one-on-one interaction with me."

\section{DISCUSSION}

Discussions of online learning and distance education encompass practical and philosophical debates on issues of purpose, style, process and policy. However, I asked the instructors in this study to describe only their online teaching within the parameters of their experiences, and the resultant discussion of their comments focuses only on teaching and learning rather than on broader online education issues, such as 
administration or policy.

In using Collins and Berge's work [13] as a framework for discussion, I was intrigued by their comment that not all four instructional roles_-pedagogical, social, managerial, and technical — would necessarily be carried out "in their entirety" by the same person. In fact, Collins and Berge thought it would be unusual if they were. Their apparent separation of online teaching from face-to-face teaching invites this question: How many traditional teachers, meeting with learners in classrooms, would not perform all four functions-technical expertise in the face-to-face environment being interpreted as using pen, paper, chalk, whiteboard, overheads or other types of demonstration hardware? This point is important to this paper because the instructors that I interviewed were experienced in face-to-face instruction and, in fact, connected most of their reflections about their online teaching to their previous experiences. Did they not expect to take responsibility for all four facets of the instructional role?

Research has indicated that learners do expect this "totality" of attention from online instructors [5, 14, 15]. What is the relationship, then, of instructors' instructional processes to their learners, given learners' expectation that online instructors will, in fact, attend to these four cornerstones of the teaching-learning transaction?

\section{A. Content and Control}

Overwhelmingly, this study's respondents' concerns revolved around the issue of content-how much and in what manner they were able to effectively transmit appropriate amounts of content to their learners. While aware of the desirability of fostering and maintaining healthy levels of student discussion in content areas, and while able to articulate their respective migrations from traditional lecturing formats to more facilitative formats, the instructors I spoke to were still predominantly content-driven. Carl and Robert worried about spending enough time on certain topic areas and were very concerned with the pacing of online discussions, using measurements of time as indicators of learners' fluency with concepts. Mark was perhaps, of this study's participants, the most content-oriented instructor, as evidenced by his responses to my questions. He repeatedly brought the conversation back to issues of textbooks and materials, and he used examples of learners' ability to master course concepts, as demonstrated by their homework assignments, to respond to questions about the quality of their online experiences as a group. In other words, for Mark, more so than for any of the other instructors, the course, and his teaching of it, was linked to his role as content expert, responsible for content delivery. Content delivery, and the pedagogy that fuels or supports it, is of course a prime outcome of most teaching experiences. It stands as one of the four cornerstone functions outlined by Collins and Berge [13] for online instruction and was articulated by Moore [24] as one of three central interactions in distance education. All distance education advocates, however, document the necessary adaptation of instructional roles from didactic lecturing to constructivist-based facilitation [12, 22, 25, 27, 31]. Similarly, online learners point out equally as vociferously their negative responses to didactically-based teaching techniques [5, 29].

\section{B. Preparing to Teach Online}

How do faculty members learn to teach online? In the large Canadian university that offered the courses discussed in this paper, a teaching and learning division regularly presented faculty-led workshops on university-appropriate topics, including online learning. Participation was voluntary. The same university also contained a technology support unit that for several years has offered individual and workshop-style instruction to faculty interested in incorporating new technologies into their teaching. Attendance, again voluntary, has over the years been populated by a small group of early adopters. 
From his experience in three Venezuelan universities, Chacon [11] concluded that preparing faculty for working in Web-based education "requires a considerable effort both from the part of the technologists who do the training and from those that receive it" (p. 2). His detailed and technical model assumes a university-supported structure that supports a process that is "not only technical in nature, but [that] also involves changes in [faculty's] perception of the subject matter, communication skills and interaction in learning communities" (p. 1). Chacon's vision, while not illogical, does not reflect most Canadian universities' responses to either faculty training or to the integration of distance technologies into traditional delivery formats.

The program under study was relatively small, fiscally-accountable in a closely-monitored cost-recovery system, and considered "high touch" by university administration. Such a system allowed me to meet with each new instructor for one-on-one coaching and hands-on demonstrations of software and course packaging. In addition to preparing the course together, new instructors and I sat together at the computer and worked through course navigation and examined and discussed course structures and the reasons for course design. Each new instructor entered his virtual classroom with knowledge of the cohort model, why it was chosen, and how such a system manifested itself in the program.

Berge [13] outlined a cluster of activities that constitute the shifting of instructional roles to more learnercentered, constructivist approaches. These activities include moving away from being "oracles" and lecturers to being consultants and resource providers, from being providers of answers to being askers of expert questions, from being designers of content to designers of learning. At the same time, instructors should move towards:

- providing only initial structures and then encouraging learners' self-direction

- presenting multiple perspectives and emphasizing salient points

- being a member of a learning team

- introducing broader systems of assessment

- co-creating, with learners, the learning space

- redefining teacher-learner power structure

Berge's typology, while speaking ostensibly to pedagogical issues and procedurally to managerial issues, implicitly also addresses the social dimension of learning. Discussed in terms of social presence and community, social issues are recognized as integral parts of healthy online learning environments $[9,15$, $18,30,21]$.

\section{Instructors' Perceptions of Learners' Socially-Constructed Community}

An important related observation concerns this study's respondents' lack of awareness of, or demonstrated interest in, the social role of instructors when engaged in online teaching. Whereas in faceto-face instruction, parts of the managerial role could be handled outside the classroom-by administrative personnel or by the registrar's office - and perhaps some of the technical role could be handed off to an audiovisual assistant, social interactions with students engendered by continual face-toface meetings are fundamental to classroom dynamics.

The data from this study renewed my interest in the relationship of the learning dynamic's constituent parts-instructional role, content, and learners-and the complexity of their interactivity [24, 30]. Can instructors who are content-centric properly appreciate the importance of creating socially-responsive collaborative learning environments? Was it possible that they participated in constructing collaborative 
learning environments without demonstrating the insight or language to describe the activities of which they were a part?

Socially-constructed environments that provide comfortable and trustworthy virtual homes to online learners have recently received more acknowledgement for their contribution to successful learning in literature [7, 10, 15, 18]. Highlighting the social peripheries "that frame human activities" [7] emphasizes the importance of learners finding balance between their communities of learning and the "other" communities that exist in their personal lives [10]. It is a striking finding of this study that the instructorparticipants did not address in any depth their efforts to create community. Nor did they dwell on their perceptions of the level of community that existed within their courses, nor did they present any conjecture about the relative existence or lack of existence of community. Even Robert, who had declared his understanding of community's importance, relegated his discussion of personal communications among learners and instructor to learning "a lot about how other people think." And Mark, for whom every interview question became a vehicle for content discussion, was unaware even of the purpose of learners' use of emoticons - a technique often used by online learners to inject a sense of personality or emotion into their contributions:

Interviewer: Did you use emoticons at all?

Mark: What?

Interviewer: The little symbols that people build into their writing to indicate...you know, a happy face, stuff like that?

Mark: No, I didn't.

Interviewer: Did any of your students?

Mark: One or two. I wondered what they were doing.

Carl's sensitivity to discussion that existed among his learners was grounded in his belief that the "natural flow" of conversation best emulated good case-study discussion and thus allowed his learners maximum opportunity to firmly grasp concepts. His distinguishing between group chat and one-on-one learnerinstructor discussion was oriented towards content and control, and it centered largely around the nature of his interaction with individual learners. "I have the hammer," he declared, referring to his control of the learning and the participation grade that was a part of the course. "Participation is $20 \%$ of the grade. If you don't participate, that's going to hurt you. And it's easy enough to remind people of that."

Finding and adopting a satisfactory stance as "facilitator" or "guide-on-the-side" can be difficult for instructors. Learners vary in their perceptions of how much leadership they want from online instructors, and their expectations are dependent on many factors. Learners just starting online courses want a functional, directed instructional presence rather than a social, interactive instructional presence [14]. Graduate learners are more likely to consider instructors as peers than are undergraduate learners [7]. In addition to sorting through learners' mixed perceptions of what they should be doing online, instructors must come to terms with their own perceptions of their roles vis-a-vis power and control issues.

The discussion of the role of ego in university teaching often does not occur or is hidden in more politically-gentle, elevated discussions of professionalism. However delicate and complex the topic, it is recognized that "many teachers are wrapped up in their own self importance and enjoy being the center of attention. The class is their stage and it provides them with an opportunity to show off their knowledge and expertise" [27]. While personal flair is often a welcome addition to classroom presentations, instructors' failure to realistically assess and evaluate the nature of their teaching skills can contribute to considerable disparity between performances in face-to-face venues and online prowess [16]. 
Gunawardena [22] writes of having to learn to "let go" of the instructional tendency to exercise control over the classroom in order to facilitate the constructive of a collaborative learning environment. The instructors in my study-Bryan, Mark, and Robert especially_spoke about their "letting go" as they analyzed their actions and the changes in their teaching habits based on adopting a more facilitative style to suit the online medium. However, their corresponding reflections on what the new interactive virtual classroom looked like were still teacher-and content-dominated. More compelling was the fact that they did not describe, or seem aware of, the existence of collaborative learner-centered social dynamics that would, in the constructivist model, replace teacher-centered learning environments.

\section{D. "We Teach Who We Are": Instructors Bringing Themselves to Their Teaching}

In their important and detailed considerations of teaching, Brookfield [6] and Palmer [26] highlighted authenticity - the personal engagement of teachers with their passion for teaching. "We teach who we are" [26] is an elegant expression of the immutability of the personality underpinning teaching with the process that contains it. That the instructors in my study "taught who they were" was one of the most striking outcomes of this research. Drawing on his particular repertoire of background experiences, each instructor brought to his new environment a framework by which to judge what he should do, how he should do it, and what the results should look like. With his background in textbook-grounded lectures, Mark's involvement with his online course centered on the learners' responses to the textbook and how that experience would translate to the online medium. Victor's background in evaluation focused his concern on ways to assess the learning that had taken place in a medium that was new to him. Carl preferred case-based seminar-style teaching over lecturing and regarded online learning as a more satisfying medium in which to practice a "natural" flow of communication. Bryan's workshop-facilitator experience underpinned his appreciation of pacing and his contemplative evaluation of the dynamics of instructor-learner interaction in terms of control and leadership. And perhaps more than his colleagues, Robert's commitment to his information-heavy technology-oriented computer course drove his conscientious preoccupation with the ways in which and the extent to which learners handled the content of the course.

\section{E. Looking Back: Instructors' Final Reflections on Their Online Experiences}

I offered the instructors in my study the opportunity to provide final reflective thoughts on their teaching by questioning them by email about six months after their second interviews. Everyone responded except Mark. Their contributions did not differ substantially from the content of their earlier interviews and the flavor of their personalities, as manifested by what they chose to talk about and the level of excitement they exhibited about certain aspects of their online teaching experiences, remained the same. Carl emphasized again the "naturalness" of the medium — natural for him because "it was constantly available to me" so that he could teach when he was "into it." They reiterated their statements of realization about the actual teaching medium: it was flexible; it was convenient; they liked it.

The period of time that elapsed between instructors' conversations with me and my final questions to them did not, for those who responded, raise any new learner-related insights, specifically around issues of community, social presence or interaction. Should a cynical enquirer wonder why the potential for such insights might exist in retrospect, I would answer with allusions to reflection and to identifying and naming the meaning of experiences after they have been lived.

I mused on a second observation that arose from Bryan's lengthy post-interview response. While he alluded to the "organizational culture of the learners as a key factor," he interpreted "program culture" in 
terms of the external factors that guided the policy and direction of the program given its role in a postsecondary institutional structure. An example would be the choice of delivery platform. Recent professional experiences had exposed him to funded collaborative projects that were exploring learning object repositories and myriad technologies such as broadband, voice-over-IP, and Flash. From this, he was deliberating on the "related lesson of the high cost of integrating ICT into my curriculum." I felt Bryan's remark indicated that his interest in online learning had shifted away from teaching and learning, perhaps reflecting that he had "lost sight of the educational process amid the crush of technology" [17].

\section{CONCLUSIONS AND IMPLICATIONS}

The purpose of this study was to explore first-time online teachers' perceptions about their experiences. The quality of their teaching was not the subject of my research nor did I attempt to collect any ancillary data such as learners' grades or course evaluation results.

Against the framework of Collins and Berge's [12] instructional roles, the instructors in my study demonstrated that their overall concerns were content-oriented. Deeming themselves the effective deliverers of that content, they wanted to ensure that they found ways for their learners to "get enough" of the content. Each instructor perceived his role and his struggle to deliver sufficient content in terms of his previous teaching experience [1]. While they acknowledged that their individual hands-on training experiences with me had been useful, they did not recount to me observations of learners' social interactivity nor did they reflect on the social aspects of their instructional roles that I had described as important to community-building activities.

Clearly, the "letting go" of old paradigms [22] had not been achieved by these instructors. And while Chacon's [11] detailed training plan for transforming classroom instructors into "virtual class mentors" acknowledges the importance of creating community, it presents no strategies for making possible that particular outcome. Novice online instructors who may be "teaching who they are" may in fact not know who their learners "are." Future research might explore ways in which new instructors can balance their concerns for content delivery more effectively against learners' needs for a sense of socially-constructed community in which they can successfully make sense of their learning.

\section{REFERENCES}

1. Annand, D. and Haughey, M. Instructors' Orientations Towards Computer-Mediated Learning Environments, 1997. Available: http://cade.athabascau.ca/vol12.1/annandhaughey.html

2. Armstrong, R. An Investigation of How Faculty Learn to Teach at a Distance with Technology: Their Strategies for Solving the Problem, 1999.

Available: http://www.edst.educ.ubc.ca/aerc/1999/99armsr.htm

3. Bates, A. Managing Technological Change: Strategies for College and University Leaders. San Francisco: Jossey-Bass. 2000.

4. Berge, Z.L. Facilitating Computer Conferencing: Recommendations from the Field. Educational Technology 35(1): 22-30, 1995.

5. Bishop, A. Come into my Parlour Said the Spider to the Fly: Critical Reflections on Web-Based Education from a Student's Perspective. Distance Education 23(2): 231-236, 2002.

6. Brookfield, S.D. The Skillful Teacher. San Francisco: Jossey-Bass, 1990.

7. Brown, R.E. The Process of Community-Building in Distance Learning Classes. Journal of Asynchronous Learning Networks 5(2): 18-35, 2001. 
8. Brown, J.S. and Duguid, P. The Social Life of Information. Boston, MA: Harvard Business School, 2000.

9. Bullen, M. Participation and Critical Thinking in Online University Distance Education. Journal of Distance Education 13(2): 1-32, 1998.

10. Cecez-Kecmanovic, D., and Webb, C. Towards a Communicative Model of Collaborative WebMediated Learning. Australian Journal of Education Technology 16(1): 73-85, 2000.

Available: http://www.ascilite.org.au/ajet/ajet16/cecez-kecmanovic.html

11. Chacon, F. Transforming Classroom Professors into Virtual Class Mentors, 2001. Available: http://www.unesco.org/iau/tfit_denmark-chacon.html

12. Collins, M. and Berge, Z.L. Facilitating Interaction in Computer Mediated Online Courses, 1996. Online. Available: http://www.emoderators.com/moderators/flcc.html.

13. Collins, M., and Berge, Z.L. Introduction to Volume Two. In: Berge, Z.L. and Collins, M.P. (Eds.), Computer Mediated Communication and the On-Line Classroom, Vol. 2: 1-10. Cresskill, NJ: Hampton Press, 1995.

14. Conrad, D. Engagement, Excitement, Anxiety and Fear: Learners' Experiences of Starting an Online Course. American Journal of Distance Education 16(4): 205-226, 2002.

15. Conrad, D. Community, Social Presence, and Engagement in Online Learning. Unpublished doctoral thesis, University of Alberta: Edmonton, Alberta, 2002.

16. Conrad, D. When Good Courses Go Bad: The Anguish of Online Dysfunctionality. Proceedings of the World conference on Educational Multimedia, Hypermedia \& Telecommunications: 322-23, 2001.

17. Daugherty, M. and Funke, B. University Faculty and Student Perceptions of Web-Based Instruction. Journal of Distance Education 13(1): 21-39, 1998.

18. Eastmond, D.V. Alone but Together: Adult Distance Study Through Computer Conferencing. Cresskill, NJ: Hampton Press, 1995.

19. Ely, M., Vinz, R., Downing, M., and Anzul, M. On Writing Qualitative Research: Living by Words. London: Falmer Press, 1997.

20. Garrison, D.R. and Archer, W. A Transactional Perspective on Teaching and Learning: A Framework for Adult and Higher Education. Amsterdam: Pergamon, 2000.

21. Gunawardena, C.N. and Zittle, F. Social Presence as a Predictor of Satisfaction within a Computer Mediated Conferencing Environment. American Journal of Distance Education 11(3): 826, 1997.

22. Gunawardena, C.N. Changing Faculty Roles for Audiographics and Online Teaching. The American Journal for Distance Education 6(3): 58-71, 1992.

23. Kanuka, H. Guiding Principles for Facilitating Higher Levels of Web-Based Distance Learning in Post-Secondary Settings. Distance Education 23(2): 163-182, 2002.

24. Moore, M.G. Three Modes of Interaction. A presentation of the NUCEA forum: Issues in Instructional Interactivity. NUCEA Conference, Salt Lake City, 1989.

25. Palloff, R.M. and Pratt, K. Building Learning Communities in Cyberspace: Effective Strategies for the Online Classroom. San Francisco: Jossey-Bass, 1999.

26. Palmer, P.J. The Courage to Teach: Exploring the Inner Landscape of a Teacher's Life. San Francisco: Jossey-Bass, 1998.

27. Panitz, T. \& Panitz, P. Encouraging the Use of Collaborative Learning in Higher Education, 1998. Online. Available: http://home.capecod.net/ tpanitz/tedsarticles/encouragingcl.htm

28. Paulsen, M.F. Moderating Educational Computer Conferences. In: Berge, Z.L. and Collins, M.P. (Eds.), Computer-Mediated Communication and the Online Classroom, Volume 3: Distance Learning, 81-90. Cresskill, NJ: Hampton Press, 1995.

29. Rimmer, S. An Online Learning Journey.

Online. Available: http://online.nmit.vic.edu.au/resources/suerimmer.htm 
30. Rourke, L., Anderson, T., Garrison, D.R., and Archer. W. Assessing Social Presence in Asynchronous Text-Based Computer Conferencing. Journal of Distance Education 14(2): 50-71, 1999.

31. Salmon, G. E-tivities: The Key to Active Online Learning. London: Kogan Page, 2002.

32. Wenger, E. Communities of Practice: Learning, Meaning and Identity. New York: Cambridge University Press, 1998.

\section{ABOUT THE AUTHOR}

Dr. Dianne Conrad is an assistant professor of adult education at the University of New Brunswick where she is responsible for the distance delivery of programs in undergraduate adult education. Her research interests include the design, development and delivery of online learning.

http://www.unbf.ca/education/welcome/people/conrad.html 